\title{
Evaluation of elution behavior and morphological change of the Cryptomeria japonica pollen grain and release of its daughter allergenic particles by air polluted rainfall
}

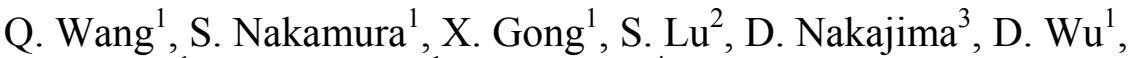 \\ M. Suzuki ${ }^{1}$, K. Sakamoto ${ }^{1} \&$ M. Miwa ${ }^{4}$ \\ ${ }^{1}$ Graduate School of Science and Engineering Saitama University, Japan \\ ${ }^{2}$ Shanghai University, China \\ ${ }^{3}$ National Institute for Environmental Studies, Japan \\ ${ }^{4}$ Center for Environmental Science in Saitama, Japan
}

\begin{abstract}
In Japan, Cryptomeria japonica pollen are scattered during each spring season. Daughter allergenic particles are released, which are smaller in size than their parent pollen grain and are abundant in a particle size below $1.1 \mu \mathrm{m}$ in the atmosphere; nevertheless, Cryptomeria japonica pollen size is about $30 \mu \mathrm{m}$. Therefore, daughter allergenic particles of pollen are transported in the urban atmosphere for a long time after their release. In particular, the daily variation delays in the peaks of allergenic Cry $\mathrm{j} 1$ concentrations of Cryptomeria japonica pollen compared with the peaks of airborne pollen counts were observed in high levels during one or two sunny days after rainfall. In addition, long range transportation of Asian dust from the East Asian continent, called yellow sand, was also found during the pollen scattering seasons in Japan, due to global warming. Therefore, the interaction between pollen and air pollutants, including yellow sand, should be of concern. Thus, in this study, the morphological change of Cryptomeria japonica pollen and the elution behavior of its allergenic contents (Cry j 1) were also investigated when in contact with simulated air polluted rain containing various crustal particles and/or secondary formed inorganic particles. As a result, pollen might burst at high humidity before
\end{abstract}


rainfall. Additionally, Cry j 1 was emitted from the so-called Ubisch body, which contains allergenic Cry $\mathrm{j} 1$ abundantly when pollen is in contact with rainfall. In particular, we found that $60 \%$ of allergenic Cry j 1 contents released in air polluted rainfall contained $\mathrm{Ca}^{2+}$ ion derived from road dust and Asian dust. Therefore, rainfall should be a main reason to induce transition of pollen allergenic contents to fine particles. In conclusion, allergenic particles that are small sized and translated as fine particles by rainfall invade into the lower respiratory tract, which can contribute to the hypersensitivity of asthma.

Keywords: Cryptomeria japonica pollen, allergenic Cry $j 1$, yellow sand, inorganic particles, air polluted rainfall, fine particles.

\section{Introduction}

Japanese cedar pollinosis has increased in Japan and now affects over $16 \%$ of the population (even up to $40 \%$ in the urban areas of Tokyo) (Nishihata et al. [1]). The prevalence is increasing in urban areas and it is currently about 28\% (Bureau of social welfare and public health, Tokyo [2]). Since the increase in the number of hay fever patients and the reduction in the age of development of symptoms, the tendency to develop of symptoms of asthmatic conditions (Maeda [3]) has also increased. In particular in recent years, it has become a big social problem, and an immediate remedy is needed. Cryptomeria japonica pollen, so-called Japanese cedar pollen, has two main allergenic contents of Cry j 1 and Cry j 2, which are the cause substances of pollinosis. One allergenic Cry j 1 exists in the pollen wall and in the so-called Ubisch body. The other allergenic Cry j 2 exists as a starch granule in the pollen grain (Nakamura et al. [4]). According to our airborne sampling, Cry j 1 contents or particles were abundant in fine particle sizes below $\mathrm{PM}_{1.1}$ and observed visually in our previous study (Wang et al. [5]). It can be explained that these allergenic contents are small sized and derived from coarse particles of original Cryptomeria japonica pollen grains (about 30 $\mu \mathrm{m})$ to fine allergen particles below $1.1 \mu \mathrm{m}\left(\mathrm{PM}_{1.1}\right)$. Therefore, these can be called daughter allergen particles of Cryptomeria japonica pollen grains. Cry $\mathrm{j} 1$ suspended fine particles were observed during sunny days after rainfall. In the Saitama urban residential area, pollen grains and allergenic daughter particles on the asphalt may also be re-suspended by heavy traffic volumes.

Inorganic ionic contents and $\mathrm{pH}$ in rainfall are changed by atmospheric conditions before rainfall, because suspended particulate matters (SPM) and gases can be uptaken by rainfall. Urban areas not only have SPM derived from natural sources, but also anthropogenic sources. These air pollutants are induced morphological change of pollen grains, such as the release of allergenic contents from pollen grains by broken pollen walls (Motta et al. [6] and Behrendt et al., [7]) and acidification of the allergen (Rogerieux et al. [8]). In addition, the long range transportation phenomena of Asian dust from the East Asian continent, called yellow sand, was found during the pollen scattering season in Japan due to global warming. Therefore, interaction between pollen and different air pollutants should be of concern. Actually, pollinosis was enhanced when pollen and soil particles, such as Kanto lome dust of Japan (Maejima et al. [9]) and 
Asian dust from the East Asian continents (Ichinose et al. [10]), were inhaled at the same time. Moreover, $\mathrm{Ca}^{2+}$ ion in rainfall was increased when Asian dust was scattering during the day (Kawamura and Hara [11]). Nevertheless, there is no research on the morphological change of Cryptomeria japonica pollen grains and their allergenic release by inorganic ionic components in rainfall. In this study, we firstly investigated the morphological change of Cryptomeria japonica pollen grains, analyzed the elution behavior of their allergenic contents and also tried to observe small sized daughter particles from parent pollen grains when contacted with simulated polluted rain water containing various inorganic ionic components.

\section{Materials and methods}

\subsection{Sampling for atmospheric particles in an urban area}

In order to grasp Cryptomeria japonica pollens and the airborne behavior of their allergenic daughter particles before and after rainfall, we collected atmospheric particles during the pollen scattering seasons (from February to March) of 2007, 2008 and 2009. Our sampling site, Saitama University, was located in the north of Tokyo metropolitan area, Japan (figure 1). All the air samples were collected on the quartz fiber filters by Andersen high-volume samplers (AH-600, Shibata Scientific Technology Ltd). This instrument collects the atmospheric suspended particulate matter equivalent to the human respiratory system as five sizesegregated particles $(<1.1,1.1-2.0,2.0-3.3,3.3-7.0,>7.0 \mu \mathrm{m})$. Because pollen allergens may exist in fine particles $\left(<1.1 \mu \mathrm{m}\right.$, so-called $\left.\mathrm{PM}_{1.1}\right)$ and coarse particles $(>7.0 \mu \mathrm{m})$ abundantly, we measured allergen concentrations in $\mathrm{PM}_{1.1}$ and $>7.0 \mu \mathrm{m}$. Air flow is $566 \mathrm{~L} / \mathrm{min}$ for each 71 hour (2007 year) and 47 hour (2008 and 2009 year) sampling during the periods. Allergenic Cry j 1 and inorganic ionic concentrations in these collected particles were measured.

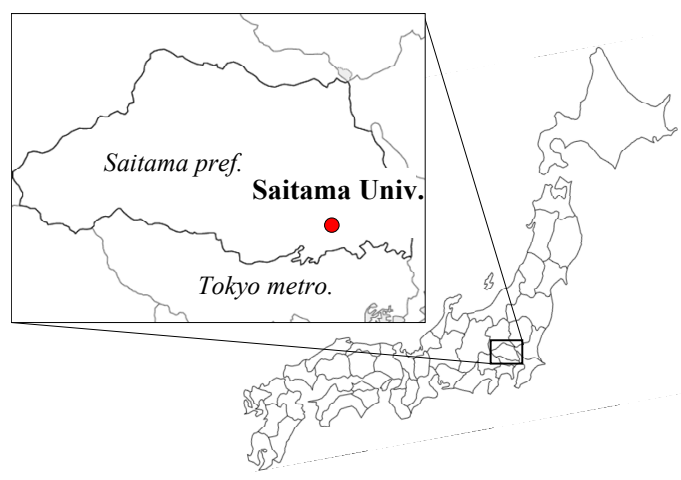

Figure 1: $\quad$ Sampling site. 
In order to count pollen in the atmosphere, airborne pollens were collected on a glass slide coated with white petrolatum and carbon tape by the Durham sampler (DK-1SA, Nishiseiki Co., Ltd.) for each 23 hour pollen collected.

\subsection{Observation of morphological change of Cryptomeria japonica pollen using an environmental scanning electron microscope}

Until now, a scanning electron microscope (SEM) had to put the samples under ultra low pressure $\left(10^{-8}-10^{-3} \mathrm{~Pa}\right)$. Therefore, pollen may burst under the experimental condition of ultra low pressure when using a traditional SEM. In this study, with the help of an environmental-SEM (ESEM), we can observe the morphological change of pollen samples under low vacuum (10-2000 Pa) even near atmospheric condition. Because of the difference of pressure between internal and external pollen, there were fewer changes than with a traditional SEM and pollen burst possibility by pressure was slim. Thus, we can investigate pollen burst by affect of only high humidity. The ESEM used was a Quanta 200 (FEI Company Co. Ltd). The pollen was set in sample room, and the morphological change of the pollen grain was examined when the internal sample room conditions were at atmospheric pressure and the humidity changed from $20 \%$ to above $100 \%$. Pictures were taken every 5 seconds, and these pictures were cascaded to make a motion picture.

The morphological change of pollen before and after contact with $1500 \mathrm{mI}$ $\mathrm{Ca}\left(\mathrm{NO}_{3}\right)_{2}$ solution was observed by an ESEM. Disseminated pollen grains on carbon tape were contacted with $1500 \mathrm{mI} \mathrm{Ca}\left(\mathrm{NO}_{3}\right)_{2}$ solution, by a solution that was fed into the sample room. After checking, the pollen was in contact with the pollen with solution, humidity was reduced and dried in the sample room and finally pollen was observed.

\subsection{Elution of pollen allergenic contents by contact with different simulated rains}

To confirm the transition of allergenic Cry $\mathrm{j} 1$ contents to fine particle sizes when in contact with rainfall, $500 \mathrm{mg}$ pollen was mixed with $\mathrm{KNO}_{3}, \mathrm{NH}_{4} \mathrm{NO}_{3}$, $\mathrm{Ca}\left(\mathrm{NO}_{3}\right)_{2}, \mathrm{NH}_{4} \mathrm{Cl},\left(\mathrm{NH}_{4}\right)_{2} \mathrm{SO}_{4},\left(\mathrm{NH}_{4}\right)_{2} \mathrm{C}_{2} \mathrm{O}_{4}$, ultra pure water and extraction solution. The extraction solution is usually prepared for the effective elution of allergenic Cry j 1 contents from pollen grains (Takahashi and Ohashi [12]). The ionic strengths of these inorganic salts were 80, 150, 500 and $1500 \mathrm{mI}$, respectively. The Cryptomeria japonica pollen solutions were made from eluted allergen contents by filtration using a cellulose acetate membrane filter (pore size is $1.2 \mu \mathrm{m})$ and pollen solutions were treated after centrifuge separation $(15,000$ $\mathrm{rpm}, 10 \mathrm{~min})$. The amount of $1 \mathrm{~mL}$ of supernatant liquids were picked and exchanged to the buffer solution (10 mM HEPES, $150 \mathrm{mM} \mathrm{NaCl}, 3 \mathrm{mM}$ EDTA, $0.005 \%$ surfactant P20) by a centrifugal filter unit (amiconultra-4, Millipore). These samples were stored below - 40 degree Celsius until our measuring experiment. 


\subsection{Measurement methods of allergenic Cry $\mathbf{j} 1$ concentrations}

The ELISA (enzyme-linked immunosorbent assay) method and the surface plasmon resonance method (SPR) (Biacore J system, GE Healthcare Co. Ltd) were used as the biochemical analyses, mainly based on the immunology to detect the presence of the antibody or its antigen in a sample.

Atmospheric Cry j 1 in these particles collected by an AH-600 sampler was measured using the ELISA method. We extracted Cry j 1 contents from the quartz fiber filter of an AH-600 sampler and used these as a sample for Cry $\mathrm{j} 1$ measurement. Cry j 1 concentrations in a sample were measured by anti-Cry $\mathrm{j} 1$ mouse monoclonal antibody (Cry j $1 \mathrm{MAb}$ ) and the enzyme mark, and finally calculated into allergenic Cry $\mathrm{j} 1$ concentration $\left(\mathrm{ng} / \mathrm{m}^{3}\right)$ in the urban atmosphere.

Eluted Cry $\mathrm{j} 1$ concentrations from pollen in contact with simulated rain were measured with a Biacore $\mathrm{j}$ system. This measuring method was adapted from the method of Takahashi and Ohashi [12]. Allergenic Cry j 1 concentrations the samples were measured based on Cry j 1 MAb immobilized on a sensor chip CM5 using the Biacore $\mathrm{j}$ system; about 14,000 RU of Cry j 1 MAb was immobilized on the chip. Finally, the results were converted into allergenic Cry $\mathrm{j}$ 1 concentrations eluted from $1.00 \mathrm{mg}$ pollen grains $(\mu \mathrm{g} / \mathrm{mg})$ in mass.

\subsection{Measurement method of pollen counts}

The counts (pollens $/ \mathrm{cm}^{2} / 23 \mathrm{~h}$ ) were carried out using a calculation of the pollen dyed using an optical microscope for the slide glass of an area of $18 \mathrm{~mm} \times 18$ $\mathrm{mm}$. Phöbus Blackly distain solution was used as the pollen dyeing solution. This distain solution was made from $0.6 \mathrm{mg}$ methyl violet $2 \mathrm{~B}, 30 \mathrm{~mL}$ phenol, $180 \mathrm{~mL}$ glycerin and $90 \mathrm{~mL}$ ultra pure water.

\subsection{Visualizing methods for confirming fine daughter allergen particles}

To confirm fine daughter allergen particles, the filter samples collected in fine particles $\left(\mathrm{PM}_{1.1}\right)$ from SPM by an AH-600 sampler described in section 2.1 were investigated using a SEM under ultra low pressure and an immunofluorescence (green) technique with a fluorescence microscope. This technique uses an antigen-antibody reaction and can investigate Cry $\mathrm{j} 1$ specifically by using Cry $\mathrm{j}$ $1 \mathrm{MAb}$, which has been developed and reported by Wang et al. [5]. In this method, the primary antibodies used was Cry j 1 MAb and FITC (Fluorescein isothiocyanate) conjugated goat anti-mouse $\mathrm{IgG}$ (Jackson Immunoresearch Laboratories, Inc.) was used as a fluorescence protein to label Cry $\mathrm{j} 1$ specifically.

\subsection{Measurement method of aqueous ion concentrations}

Aqueous ions $\left(\mathrm{Na}^{+}, \mathrm{NH}_{4}^{+}, \mathrm{K}^{+}, \mathrm{Mg}^{2+}, \mathrm{Ca}^{2+}, \mathrm{F}^{-}, \mathrm{Cl}^{-}, \mathrm{NO}_{3}^{-}, \mathrm{SO}_{4}{ }^{2-}\right)$ from a quartz fiber filter of an AH-600 sampler were also measured by an ion chromatograph. Aqueous ions were extracted by ultrasonic extraction. Finally, ion concentrations were converted into ion concentration $\left(\mu \mathrm{g} / \mathrm{m}^{3}\right)$ in the urban atmosphere. 


\section{Results and discussions}

\subsection{Airborne behavior of pollen counts and size-segregated allergenic particles before and after rainfall}

Figure 2 indicates time variations of allergenic Cry j 1 concentrations and pollen counts during March $10^{\text {th }}-23^{\text {rd }}, 2008$ ) in Saitama, Japan. Cry j 1 concentrations in the atmosphere almost existed in $\mathrm{PM}_{1.1}$. In particular, Cry $\mathrm{j} 1$ concentrations in $\mathrm{PM}_{1.1}$ were increased on sunny days after heavy rain, $26 \mathrm{~mm}$ during March $19^{\text {th }}$ $20^{\text {th }}$. Other rainy days were March $10^{\text {th }}\left(8 \mathrm{~mm}\right.$ rainfall) and March $14^{\text {th }}(5 \mathrm{~mm}$ rainfall). Since rainfall on March $10^{\text {th }}$ and March $14^{\text {th }}$ occurred in the morning of March $10^{\text {th }}$ and from $16: 00$ on March $14^{\text {th }}, 2008$, before or after pollen scattering time, the decrease of pollen counts and Cry $\mathrm{j} 1$ concentrations were not so obvious.

Cry $\mathrm{j} 1$ concentration ratios between $\mathrm{PM}_{1.1}$ and coarse particles $(>7.0 \mu \mathrm{m})$ before and after rainfall are shown in figure 3 . Cry $\mathrm{j} 1$ concentration ratios increased after rainfall compared to before rainfall. The correlation of Cry $\mathrm{j} 1$ contents between $\mathrm{PM}_{1.1}$ and $>7.0 \mu \mathrm{m}$ after rainfall were quite poor $(\mathrm{R}=0.31, \mathrm{n}$ $=20)$, whereas a good correlation of Cry j 1 concentrations was shown $(\mathrm{R}=$ $0.90, \mathrm{n}=20)$ between $\mathrm{PM}_{1.1}$ and coarse particles $(>7.0 \mu \mathrm{m})$ before rainfall. When pollen counts were compared between before and after rainfall, average pollen counts before rainfall were $167.6 \pm 137.3$ (counts $/ \mathrm{cm}^{2} / 23 \mathrm{~h}$ ). By contrast, the average pollen counts after rainfall were $125.0 \pm 84.4$ (counts $/ \mathrm{cm}^{2}$ / $23 \mathrm{~h}$ ).

Therefore, Cry j 1 concentrations in $\mathrm{PM}_{1.1}$ after rainfall could possibly be contributed to something other than pollen counts suspended in the atmosphere. Bartkova [13] reported that Betula, Poaceae, Ambrosia artemisiifolia pollen counts were reduced after rainfall days. In addition, Schappi et al. [14] also showed that fine birch allergen particles increased at rainfall. In our observation,

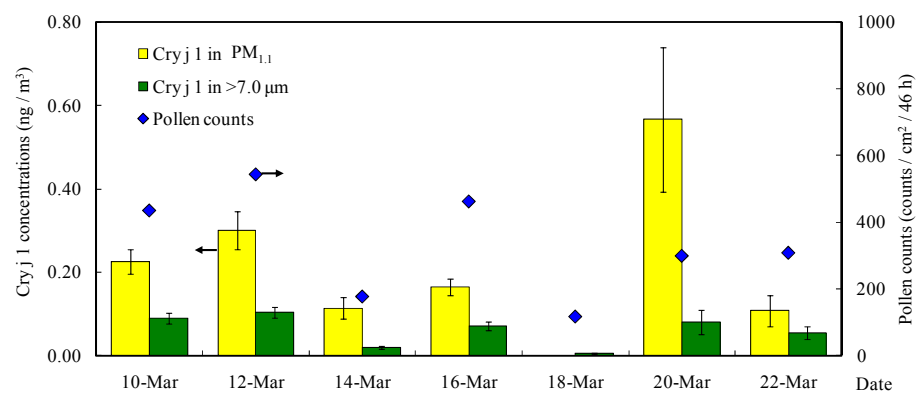

Figure 2: Time variations of Cry $\mathrm{j} 1$ concentrations and pollen counts (March $10^{\text {th- }} 23^{\text {rd }}, 2008$ ) in Saitama, Japan. 


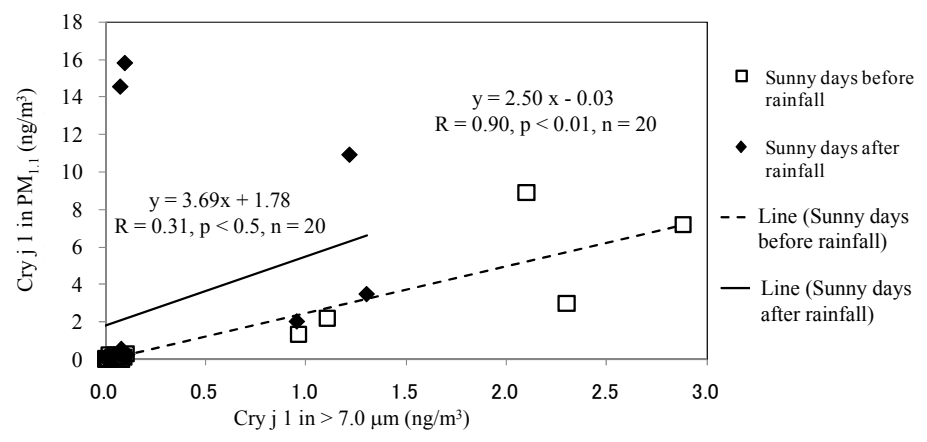

Figure 3: Comparing allergenic Cry j 1 concentration ratios between fine particles $\left(\mathrm{PM}_{1.1}\right)$ and coarse particles $(>7.0 \mu \mathrm{m})$ before and after rainfall based on our field investigations.
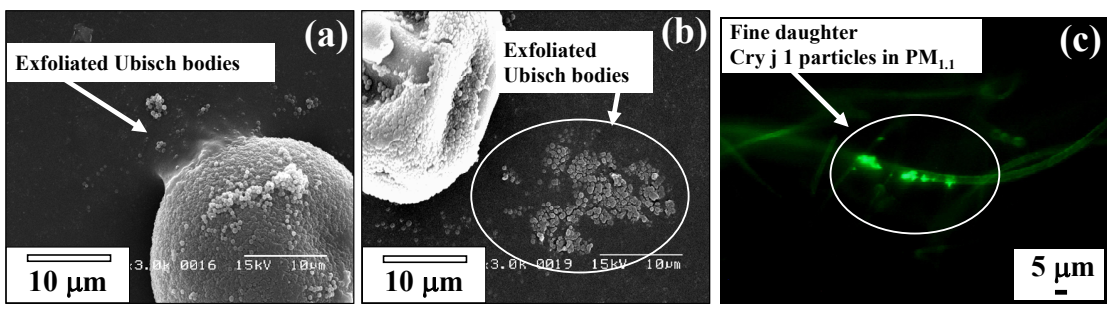

Figure 4: $\quad$ Images ((a) and (b)) of fine daughter allergenic particles by a SEM and immunofluorescence luminescent spots (c) on the fiber filter.

the results of Cryptomeria japonica pollen and allergenic contents were also similar. Schappi et al. [15] reported that pollen in contact with rainfall was examined, showing the growth of pollen tubes and the release of starch granules containing allergenic contents. Thus, allergenic particles that came to fine particles were resuspended on sunny days after rainfall. Therefore, one cause of the increase in fine allergenic particles on sunny days after rainfall was thought to be fine allergenic particles that were released by rainfall and resuspended in the urban atmosphere.

\subsection{Validation of visualizing fine daughter allergenic particles in $\mathbf{P} \mathbf{M}_{1.1}$}

In figures 4(a) and 4(b), Ubisch bodies contained Cry j 1 were observed by a SEM, which were released from its original pollen grain. In addition, with the observation of the immunofluorescence technique, it was possible to find the green fluorescence luminescent spots shown in figure 4(c)) on the quartz fiber filter. 
Therefore, Cry j 1 particles were below $1.1 \mu \mathrm{m}$ and their forms clearly differ from pollen grains by about $30 \mu \mathrm{m}$. From these results, we can confirm the existence of fine daughter allergen particles of exfoliated Ubisch bodies, which when suspended in the atmosphere can invade the lower human respiratory system tract.

\subsection{Aqueous inorganic ionic concentrations in the atmosphere before rainfall}

The average aqueous inorganic ionic concentrations before rainfall are shown table 1. The concentrations of $\mathrm{NO}_{3}{ }^{-}$and $\mathrm{SO}_{4}{ }^{2-}$ were high. $\mathrm{Na}^{+}, \mathrm{NH}_{4}{ }^{+}, \mathrm{Ca}^{2+}$ and $\mathrm{Cl}^{-}$ were the next highest. $\mathrm{NO}_{3}^{-}, \mathrm{SO}_{4}{ }^{2-}$ and $\mathrm{NH}_{4}{ }^{+}$were emitted vehicle emissions or secondary formation. Therefore, heavy traffic areas, such as the Saitama urban area, showed increased ionic components. $\mathrm{Ca}^{2+}$ was contained in crustal particles and/or yellow sand (Ma et al. [16]) from the East Asian continent.

\subsection{Morphological change of pollen grain with high-humidity}

The burst phenomena of Cryptomeria japonica pollen with the increment of high-humidity is indicated in figure 5 with the help of an environmental-SEM (ESEM). In the increasing humidity, the pollen grains were swollen. After about

Table 1: Average inorganic ions in the atmosphere before rainfall.

\begin{tabular}{cccccccccc}
\hline & \multicolumn{8}{c}{ Ion concentrations $\left(\mu \mathrm{g} / \mathrm{m}^{3}\right)$} \\
\cline { 2 - 9 } & $\mathrm{Na}^{+}$ & $\mathrm{NH}_{4}^{+}$ & $\mathrm{K}^{+}$ & $\mathrm{Mg}^{2+}$ & $\mathrm{Ca}^{2+}$ & $\mathrm{F}^{-}$ & $\mathrm{Cl}^{-}$ & $\mathrm{NO}_{3}{ }^{-}$ & $\mathrm{SO}_{4}{ }^{2-}$ \\
\hline $\begin{array}{c}\text { Avarage } \\
\text { Standard } \\
\text { deviation }\end{array}$ & 1.29 & 2.33 & 0.40 & 0.26 & 1.32 & 0.47 & 1.15 & 8.18 & 8.25 \\
\hline
\end{tabular}
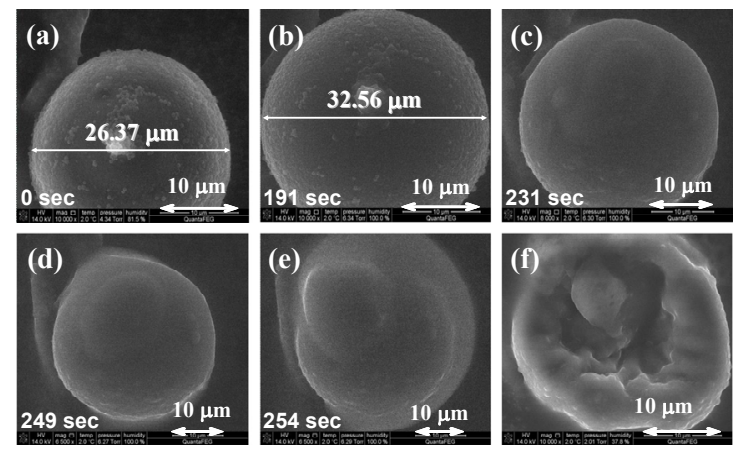

Figure 5: Morphological changes of Japanese cedar pollen under (a): low humidity; (b): high humidity; (c): more swollen; (d): pollen burst; (e): inner cells diffused; and (f): after burst. 
4 minutes from the humidity becoming $100 \%$, the pollen burst and released the inner cells. Comparing particle sizes of normal pollen grain (figure 5(a)) and adjacent (figure 5(b)) burst, whereas normal pollen size was $26.37 \mu \mathrm{m}$, pollen size at adjacent burst became large at $32.56 \mu \mathrm{m}$. With this result, we can successfully investigate pollen burst phenomena by changing only the humidity. Because the allergenic contents contained starch granules, pollen burst by high humidity before rainfall also contributed to an increase of fine allergenic particles.

\subsection{Morphological changes of pollen grain when in contact with a simulated rain containing $\mathrm{Ca}\left(\mathrm{NO}_{3}\right)_{2}$}

From the morphological observation shown in figure 6, Ubisch bodies on the surface of pollen were fine particles, approximately hundreds of nanometers. Ubisch bodies in contact with a $\mathrm{Ca}^{2+}$ rich solution (figure $6(\mathrm{~d})$ ) were eluted with slippery surfaces.

Because allergenic Cry j 1 contents exist in Ubisch bodies of Cryptomeria japonica pollen, allergenic Cry $\mathrm{j} 1$ contents were small sized to fine daughter allergenic particles by contact with rainfall. Therefore, rainfall is one cause of the release of fine allergenic particles.

\subsection{Investigation of the eluted concentration of allergenic Cry $\mathbf{j} 1$ from Cryptomeria japonica pollen}

Eluted allergenic Cry j 1 concentrations from Cryptomeria japonica pollen when in contact with various simulated rains are indicated in figure 7.

The broken lines show the ballpark allergenic Cry j 1 contents analyzed by extraction solution. Comparing the cations (figure 7(a)) and anions (figure 7(b)) effects, the Cry j 1 contents were most effectively eluted in simulated rain water that contained $\mathrm{Ca}^{2+}$ ion. About $60 \%$ of the allergenic Cry j 1 concentrations were eluted from pollen when in contact with simulated rain containing $\mathrm{Ca}^{2+}$ ions, compared with the extraction solution. In the anion effect, simulated rain

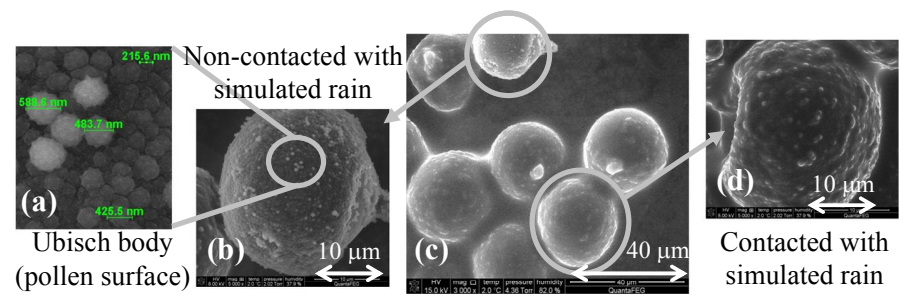

Figure 6: Morphological change of pollen grain by a SEM: (a) Ubisch bodies approximately hundreds of nanometers; (b) original pollen grains (non-contacted with solution); and (c) and (d) pollen grains in contact with $1500 \mathrm{mI} \mathrm{Ca}\left(\mathrm{NO}_{3}\right)_{2}$ solution, respectively. 

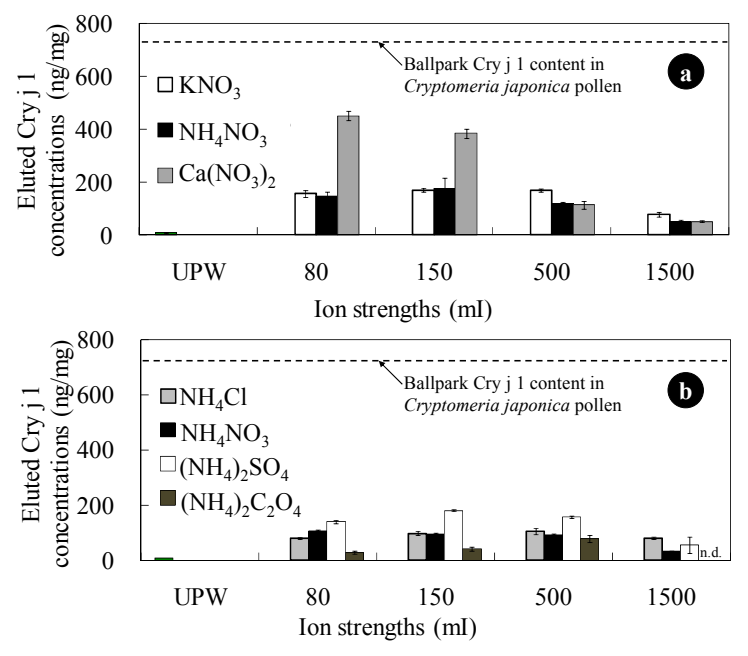

Figure 7: Elution tendency of allergenic Cry $\mathrm{j} 1$ concentrations in various ion strengths and salt components, when cations (a) and anions (b) contents and ion strengths were changed. Broken lines are ballpark Cry $\mathrm{j} 1$ content analyzed by solution that elutes from pollen grain effectively. The meaning of UPW is ultrapure water.

containing $\left(\mathrm{NH}_{4}\right)_{2} \mathrm{SO}_{4}$ was more eluted than other anions. However, $\left(\mathrm{NH}_{4}\right)_{2} \mathrm{SO}_{4}$ was not affected by $\mathrm{Ca}^{2+}$ ions. Inorganic ions, such as $\mathrm{NH}_{4} \mathrm{NO}_{3}, \mathrm{NH}_{4} \mathrm{Cl}$, $\left(\mathrm{NH}_{4}\right)_{2} \mathrm{SO}_{4}$ and $\left(\mathrm{NH}_{4}\right)_{2} \mathrm{C}_{2} \mathrm{O}_{4}$ used in this study, were well known as secondary formed particles and air pollutions. Additionally, $\mathrm{Ca}\left(\mathrm{NO}_{3}\right)_{2}$ was formed from the neutralization reaction between $\mathrm{Ca}$ rich Asian dusts (Ma et al. [16]) from the East Asian continent and acidity air pollutions emitted from industry, etc., in China and Japan.

In this result, allergenic contents from Cryptomeria japonica pollen were more eluted when in contact with rain water containing air polluted ions, moreover rainfall contained mineral ion derived from Asian dust and crustal particles had a greater elution effect. However, because eluted allergenic concentrations were decreased when the simulated rains had few ions and high ionic strength, we need to investigate rainfall during the long range transportation of Asian dust to Japan.

\section{Conclusion}

We investigated the airborne behavior of Cryptomeria japonica pollen and its small sized allergenic particles, the so-called daughter allergenic particles from the pollens, before and after rainfall. From our sampling results, allergenic Cry j 1 concentration ratios between fine and coarse particles were increased after rainfall compared with before rainfall. In other words, fine allergenic particles were increased; nevertheless coarse allergenic particles and pollen 
counts were decreased. At the same time, it is found that there is a poor correlation between Cry $\mathrm{j} 1$ concentrations of $\mathrm{PM}_{1.1}$ and that of coarse particles $(>7.0 \mu \mathrm{m})$ after rainfall. Therefore, fine allergen particles after rainfall were increased by pollens suspended before rainfall, were taken up by raindrops and eluted as fine allergenic particles. Small sized allergenic particles from the pollens other than Cryptomeria japonica pollen were reported (Auli et al., [17]); the release of pollen allergen was not reported under the same conditions. Therefore, in our study, the small sized phenomena of Cryptomeria japonica pollen allergens and daughter allergenic particles released from its original pollen by rainfall were firstly reported.

From our field sampling studies we thought that rainfall was one of the release causes of fine allergen particles. Therefore, we tried experiments with simulated polluted rain. In the supposed high humidity experiment with adjacent rainfall, Cryptomeria japonica pollen burst under the high humidity. Until now, traditionally a SEM was needed with high vacuum conditions. Therefore, it was possible for the high vacuum to burst the pollen grain. However, an ESEM can investigate under low vacuum conditions. We became successful in investigating pollen burst phenomena with the change of humidity. In addition, morphological changes and the behavior of eluted allergenic concentrations from the original pollen in simulated rain solutions of different cations and anions were also investigated. With the help of this result, we can explain that the daughter allergenic particles may be released as fine particles from their parent pollen during sunny days after $\mathrm{Ca}^{2+}$ rich rainfall, despite decreased pollen counts. Additionally, the released allergenic particles concentrations from pollen were increased $(60 \%)$ when in contact with simulated rain containing Asian dust from the East Asian continent.

Wang et al. [18], Kurihara et al. [19] and Okuyama et al. [20] also reported that the deposition on the surface of pollen grains in urban area were adhered with other airborne particles, such as crustal particles and/or secondary formed particles. Therefore, complex airborne particles, for example pollen with other particles, in contact with rain drops and the moistening of pollen surfaces by high humidity induced regional high ionic strengths on pollen surfaces.

From our experimental results, air polluted rainfall contained abundant aqueous inorganic ions that induced the elution and release of allergenic contents, which are as small sized as fine particles from Cryptomeria japonica pollen grains. Then, after they were dried during sunny days, the allergenic particles can be re-suspended to translate to fine particles by wind or heavy traffic in the urban residential atmosphere. In addition, fine allergen particles proceed indoors, since they easily break through doors and windows. Fine allergenic particles will invade the lower respiratory tract, which can contribute to the hypersensitivity of asthma.

\section{Acknowledgements}

Some works of this study were supported by the Special Funds for Basic Research (B) (No. 17310031, FY2005 FY2007) of Grant-in-Aid for Scientific 
Research of the Japanese Ministry of Education, Culture, Sports, Science and Technology (MEXT) and the FY2007 FY2008 Research project of Innovative Research Organization, Saitama University, Japan.

\section{References}

[1] Nishihata, S., Inoue, S., Saiga, T., Sahashi, N., Suzuki, S., Murayama, K., Yokoyama, T., and Saito, Y., Prevalence rate of allergy to Japanese Cedar Pollen in Tokyo, The Japanese Society of Allergology, 48(6), 597-604, 1999 (in Japanese).

[2] Bureau of social welfare and public health, Tokyo metropolitan government, The report of the actual condition for pollinosis sufferers, 2225, 2007 (in Japanese).

[3] Maeda, Y., Pollen asthma and that treatment, Allergy in Practice, 22, 3438, 2002 (in Japanese).

[4] Nakamura, S., Sato, F., Nakamura, N., Immunocytochemical localization of Cry j 1 and Cry j 2 - the allergenic proteins of Japanese cedar pollen - in the germinated pollen, Japanese journal of palynology, 50(1), 15-22, 2004 (in Japanese).

[5] Wang, Q., Kurihara, K., Kiryu, H., Sakamoto, K., Miwa, M. and Uchiyama, I., Daily variation differences between airborne Japanese cedar pollen and its respirable allergen particulate matters during the most severe pollination seasons, Earozoru Kenkyu, 23, 120-126, 2008 (in Japanese).

[6] Motta, A.C., Marliere, M., Peltre, G., Sterenberg, P.A., Lacroix G., TrafficRelated Air Pollutants Induce the Release of Allergen- Containing Cytoplasmic Granules from Grass Pollen, Int Arch Allergy Immunol, 139, 294-298, 2006.

[7] Behrendt, H., Becker, W. M., Fritzsche, C., Sliwa-Tomczok, W., Tomczok, J., Friedrichs, K. H., Ring, J., Air pollution and allergy: Experimental studies on modulation of allergen release from pollen by air pollutants, International Archives of Allergy and Immunology, 113, 69-74, 1997.

[8] Rogerieux, F., Godfrin, D., Sènèchal, H., Motta, A. C., Marlière, M., Peltre, G, Lacroix, G., Modifications of Phleum pretense Grass Pollen Allergens following Artificial Exposure to Gaseous Air Pollutants $\left(\mathrm{O}_{3}, \mathrm{NO}_{2}, \mathrm{SO}_{2}\right)$, International Archives of Allergy and Immunology, 143, 127-134, 2007.

[9] Maejima, K., Tamura, K., Nakajima, T., Taniguchi, Y., Saito, S., Takenaka, H., Effects of the inhalation of diesel exhaust, Kanto loam dust or diesel exhaust without particles on immune responses in mice exposed to Japanese cedar (Cryptomeria japonica) pollen, Inhalation Toxicology, 13, 1047-1063, 2001.

[10] Ichinose, T., Hiyoshi, K., Yoshida, S., Takano, H., Inoue, K., Nishikawa, M., Mori, I., Kawazato, H., Yasuda, A., Shibamoto, T., Asian sand dust aggravates allergic rhinitis in guinea pigs induced by Japanese cedar pollen, Inhalation Toxicology, 21(12), 985-993, 2009. 
[11] Kawamura, C. and Hara, H., Influence of Kosa in precipitation chemistry in Japan, Japan society for atmospheric environment, 41(6), 335-346, 2006 (in Japanese).

[12] Takahashi, Y., and Ohashi, T., Real-time measurement of airborne pollen allergen applied the surface Plasmon resonance (SPR). The Japanese Society of Allergology, 51(1), 24-29, 2002 (in Japanese).

[13] Bartkova, S. J, The influence of temperature, relative humidity and rainfall on the occurrence of pollen allergens (Betula, Poaceae, Ambrosia artemisiifolia) in the atmosphere of Bratislava (Slovakia), Int $J$ Biometeorol, 48, 1-5, 2003.

[14] Schappi, G. F., Taylor, P. E., Staff, I. A., Rolland, J. M., Suphioglu, C., Immunologic significance of respirable atmospheric starch granules containing major birch allergen Bet v 1, Allergy, 54(5), 478-483, 1999.

[15] Schappi, G. F., Taylor, P. E., Staff, I. A., Suphioglu, C., Knox, R. B., Source of Bet v 1 loaded inhalable particles from birch revealed, Sex Plant Reprod, 10, 315-323, 1997.

[16] Ma, C., Kasahara, M., Holler, R., and Kamiya, T., Characteristics of single particles sampled in Japan during the Asian dust-storm period, Atmospheric Environmental, 35, 2707-2714, 2001.

[17] Auli, R. L., Matikainen, E., pollen Allergen reports help to understand preseason symptoms, Aerobiologia, 18, 135-140, 2002.

[18] Wang, Q., Gong, X., Nakamura, S., Kurihara, K., Suzuki, M., Sakamoto, K., Miwa, M., Lu, S., Air pollutant deposition effect and morphological change of Cryptomeria japonica pollen during its transport in urban and mountainous areas of Japan, Environmental Health Risk V, Biomedicine and Health, 14, 77-89, 2009.

[19] Kurihara, K., Wang, Q., Kiryu, H., Sakamoto, K., Miwa, M. and Uchiyama, I., , Airborne behavior of suspended particulate matters containing Japanese cedar pollen allergens in urban, roadside and mountain areas of Saitama, Japan, Journal of Japan Society for Atmospheric Environment, 42, 362-368, 2007 (in Japanese).

[20] Okuyama, Y., Matsumoto, K., Okochi, H., Igawa, M., Adsorption of air pollutants on the grain surface of Japanese cedar pollen, Atmospheric Environment, 41, 253-260, 2007. 